\title{
Survivin Expression in Ovarian Carcinoma: Correlation with Apoptotic Markers and Prognosis
}

\author{
Cynthia Cohen, M.D., Christina M. Lohmann, M.D., George Cotsonis, Ph.D., Diane Lawson, M.T., \\ Robert Santoianni, HTL (ASCP) \\ Departments of Pathology and Laboratory Medicine (CC, CML, DL, RS) and Public Health (GC), Emory \\ University School of Medicine, Atlanta, Georgia
}

\begin{abstract}
Survivin is a novel inhibitor of apoptosis commonly detected in tissues during fetal development and in cancer, but not usually in normal tissues. Expression of this protein may be of prognostic significance and therapeutically relevant in many cancers. We assessed survivin expression in ovarian carcinoma, correlating results with expression of other anti-apoptotic (bcl-2, bcl-x, mutant p53) and proapoptotic (bax) markers, with prognostic parameters, and prognosis. Paraffin-embedded sections of 49 ovarian carcinoma were immunostained for survivin, bcl-2, bcl-x, bax, and p53. Expression was evaluated in nuclei and cytoplasm, as intensity (0$3+$ ), and percentage of positive cells was scored on a four-tiered system with $<10 \%$ as negative. Frequency of survivin, bcl-2, bcl-x, bax, and p53 was $73.5 \%, 36.7 \%, 93.9 \%, 77.6 \%$, and $60.4 \%$, respectively. There was significant correlation between nuclear survivin expression and grade $(P=.0014)$, histologic type $(P=.0376)$, and mutant p53 $(P=$ .0414). Survivin expression did not correlate with bcl-2, bcl-x, or bax expression, stage, or overall or disease-free survival. The majority $(74 \%)$ of ovarian carcinoma show survivin expression, which correlates with poor prognostic parameters (high grade, histologic type, p53 mutation) but not with survival. Therapeutic targeting of survivin in ovarian carcinoma is a future possibility.
\end{abstract}

KEY WORDS: Ovarian carcinoma, Immunohistochemistry, Inhibitor of apoptosis proteins (IAP), Survivin.

Mod Pathol 2003;16(6):574-583

\footnotetext{
Copyright $\odot 2003$ by The United States and Canadian Academy of Pathology, Inc.

VOL. 16, NO. 6, P. 574, 2003 Printed in the U.S.A.

Date of acceptance: March 28, 2003.

Presented at the International Academy of Pathology, Amsterdam, Netherlands, in October 2002.

Address reprint requests to: Cynthia Cohen, M.D., Anatomic Pathology, Emory University Hospital, G144, 1364 Clifton Road NE, Atlanta, GA 30322; fax: 404-712-4754; e-mail: ccohe01@emory.edu.

DOI: 10.1097/01.MP.0000073868.31297.BO
}

The human survivin gene spans $14.7 \mathrm{~kb}$ on telomeric position of chromosome 17 and is localized to band q25 $(1,2)$. Survivin protein has the ability to suppress apoptosis (programmed cell death) and regulate cell division (2). Although not present in most normal adult differentiated tissues, its mRNA and the protein are present in large amounts in fetal tissue. Most cancers, regardless of lineage, differentiation, and histologic type, overexpress survivin, suggesting reactivation of the gene (1) and a potential target for drug therapy (3).

Survivin is a member of the inhibitor-of-apoptosis proteins (IAP) family $(4,5)$. The possible mechanism whereby it blocks apoptosis is via an effect on caspase-9, which is activated via extrinsic and intrinsic pathways $(5,6)$. In the latter cell death pathway, upstream stimuli such as activation of p53 induce expression of pro-apoptotic bcl-2 family proteins such as bax. Anti-apoptotic proteins such as bcl-2 and bcl- $\mathrm{X}_{\mathrm{L}}$ inhibit the membrane-permeabilizing effects of bax and other pro-apoptotic proteins and also may inactivate caspase- 9 by binding to, and inactivating, the adapter protein Apaf-1 (7, 8). Hence, caspase-3 and other downstream effector caspases are not activated, and apoptosis is inhibited. Survivin suppression of apoptosis is thought to be at the level of caspase 9, where it causes dissociation of the Apaf-1caspase 9 complex. Caspase- 3 is not activated, and apoptosis is inhibited $(4,9)$.

Survivin's interaction with the mitotic spindle apparatus may be essential for its anti-apoptotic function. Disruption of the survivin-microtubule interactions that occur at the beginning of mitosis results in increased caspase- 3 activity with loss of the anti-apoptotic function of survivin (10). Survivin expression in carcinoma nuclei or by reverse transcriptase polymerase chain reaction (RT-PCR) is shown to strongly correlate with proliferation index in hepatocellular (11), endometrial $(10,11)$, and ovarian $(12,13)$ carcinoma. It is felt that survivin promotes cell proliferation by interacting with Cdk4 with the release of p21 (11). 
Survivin expression correlates with more aggressive behavior in colorectal $(5,14)$ and gastric (15) carcinoma and in neuroblastoma (16), with increased recurrences and metastases and reduced life expectancy (17). It is associated with reduced apoptosis in vivo (17). Because most anticancer chemotherapy kills cancer cells by activating apoptosis, increased survivin expression may decrease effectiveness of such therapy. Thus, survivin antagonists may be beneficial in treatment of such cancers (lymphoma, malignant melanoma, breast, cervix, prostate, lung, colorectal, and basal and squamous cell skin cancers) $(3,5,18-26)$.

We studied the frequency of survivin expression in human ovarian carcinoma to assess the possible future role for therapies that inactivate this protein and, hence, increase apoptosis. Survivin expression also was correlated with expression of bcl-2, bcl-x, and mutant p53 (anti-apoptotic markers) and of bax (a pro-apoptotic marker), with clinicopathologic prognostic parameters, and with outcome.

\section{MATERIALS AND METHODS}

Forty-nine ovarian carcinoma diagnosed consecutively in the Department of Pathology, Emory University Hospital, Atlanta, Georgia between 1984 and 1995 were studied, provided paraffin blocks were available. They were graded as 1 to 3 (well, moderately, and poorly differentiated, respectively) on the basis of cellular atypia, architectural complexity, and invasive propensity (27). FIGO staging was based on findings at clinical examination and by surgical exploration. Stage I represents growth limited to the ovaries, Stage II involves one or both ovaries with pelvic extension, Stage III includes tumors that involve one or both ovaries with peritoneal implants outside the pelvis and/or positive retroperitoneal or inguinal nodes, and Stage IV represents tumors with distant metastases (27). Clinicopathologic parameters and follow-up were obtained from surgical pathology reports and from the Oncology Data Bank, Winship Cancer Center, Atlanta, Georgia.

\section{Immunohistochemistry}

Five-micrometer sections of the formalin-fixed, paraffin-embedded tumors were immunostained, after steam heat-induced epitope retrieval, using polyclonal survivin (1:80; Santa Cruz Biotechnology, Santa Cruz, CA), monoclonal bcl-2 (1:160; Onc 124; DAKO, Carpinteria, CA), polyclonal bcl-x (1: 1500; PharMingen, San Diego, CA), polyclonal bax (1:1500; PharMingen), and monoclonal p53 (1:20; DO-7; Novocastra, Newcastle upon Tyne, UK). For survivin, an avidin biotin-complex kit (LSAB + System; DAKO) was used with the DAKO Autostainer.
With the other four antisera, an avidin biotin enzyme-complex kit (Signet Laboratories Inc., Dedham, MA) was used in combination with the automated TechMate 1000 immunostaining system (Biotek Solutions Inc., Santa Barbara, CA; 28). Hematoxylin was used as counterstain for survivin and p53, and hematoxylin and eosin, as counterstains for the other three antigens. Sections of colonic adenocarcinoma were used as positive controls for survivin (Fig. 1) and p53, tonsil for bcl-2, and normal breast ducts and lobules for bcl-x and bax. Negative controls had primary antibody replaced by buffer. The three polyclonal antibodies acted as isotype-specific controls for each other. The survivin antibody used has been shown to react specifically with survivin of human origin by Western blotting and immunohistochemistry (IHC). Immunostain was recorded as $0-3+$ according to stain intensity, distribution in cytoplasm and/or nucleus, and percentage of cancerous cells that stained positively. Tumors were scored on a four-tiered system, with $<10 \%$ of carcinoma cells staining called negative; $10-25 \%$ positivity scored as $1,26-50 \%$ scored as $2,51-75 \%$ scored as 3 , and $76-100 \%$ scored as 4 .

\section{Statistics}

Survivin expression was compared with age, using a $t$ test and compared with other categorical factors using Fisher's exact test. Kaplan-Meier methods were used to calculate overall survival rates and disease-free survival rates among different groups. These groups were then compared using log-rank methods. Because of small sample size and the fact that few univariate results were significant, no multivariate methods were used.

\section{RESULTS}

Table 1 indicates the frequency in ovarian carcinoma of survivin and apoptotic marker expression as $74 \%, 37 \%, 94 \%, 78 \%$, and $60 \%$ for survivin (Figs. 1 and 2), bcl-2, bcl-x, bax, and p53 (Fig. 3), respectively.

Table 2 documents the clinical and pathologic features of the 49 ovarian carcinoma studied, according to whether survivin expression was present or not. Histologic grade (Grades 2 and 3; $P=.0014$ ), histologic type (serous and poorly differentiated; $P=.0376)$, and p53 mutation $(P=.0414)$ were significantly associated with survivin expression. The number of endometrioid and mucinous carcinomas was too small for assessment of association. Although patient age tended to be older in patients with survivin expression in their carcinoma, none of the other parameters (clinical stage; expression of bcl-2, bcl-x, or bax) were significantly associated with survivin expression. 


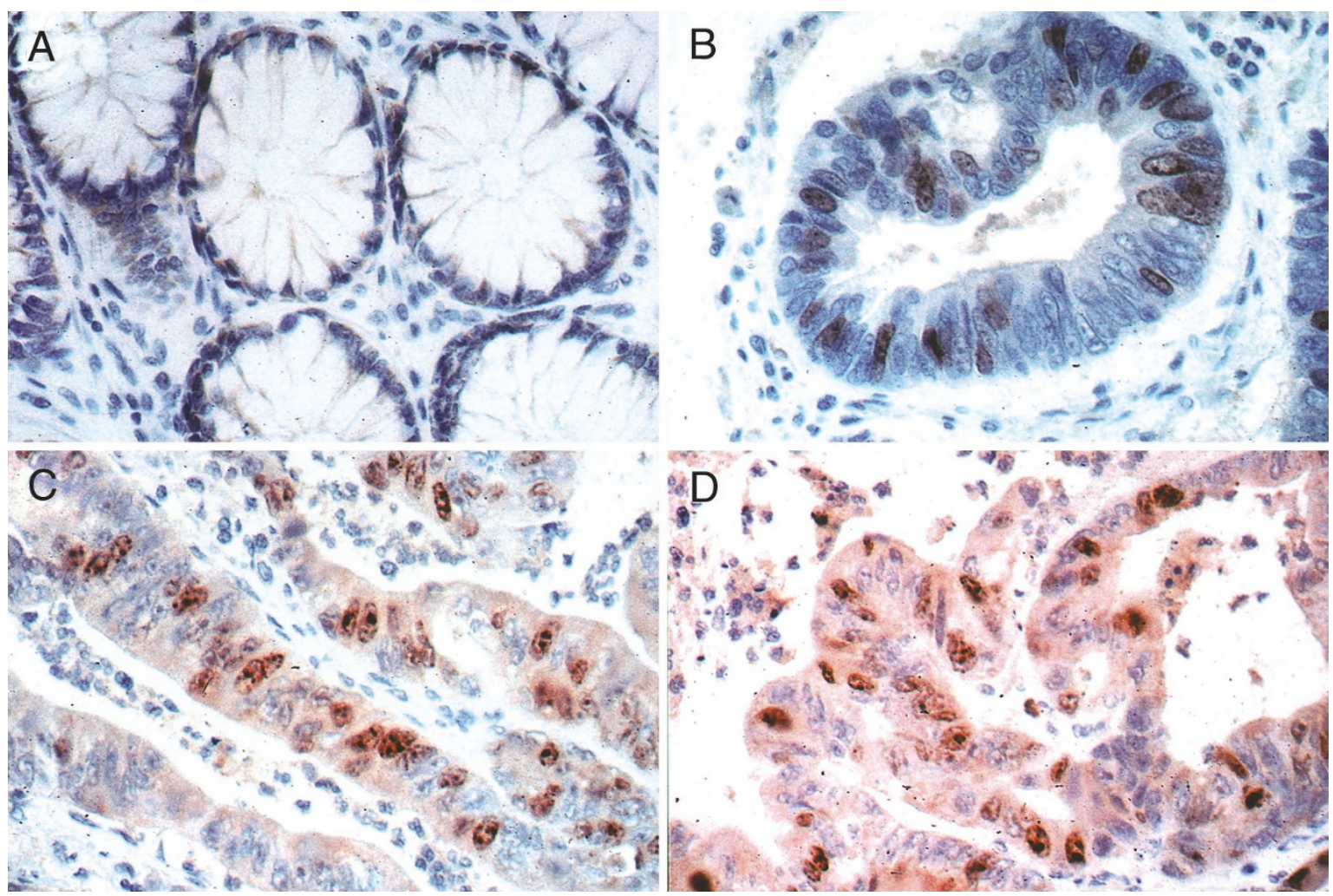

FIGURE 1. Survivin expression that is absent in normal colon (A); in nuclei of colon cancer (B); and in nuclei of two papillary serous carcinomas of the ovary (C and D). Magnification, $400 \times$.

TABLE 1. Frequency of Expression of Survivin and Apoptotic Markers in 49 Ovarian Carcinoma

\begin{tabular}{lc}
\hline & Positive Number (\%) \\
\hline Survivin & $36(74 \%)$ \\
bcl-2 & $18(37 \%)$ \\
bcl-x & $46(94 \%)$ \\
bax & $38(78 \%)$ \\
p53 (48) & $29(60 \%)$ \\
\hline
\end{tabular}

Table 3 correlates overall and disease-free survival in 44 ovarian carcinoma patients according to whether survivin or the other apoptotic markers studied were present or absent. The mean overall survival obtained for these 44 patients was 4.4 years (range, 0.2-13.5 y). Mean disease-free survival was 3.8 years (range, $0.2-13.5$ y). Expression of none of these markers was predictive or prognostic of improved overall or disease-free survival in ovarian carcinoma patients.

\section{DISCUSSION}

Strong survivin expression has been demonstrated in solid malignancies of the lung (29), colon (30), pancreas (31), stomach $(15,32)$, esophagus (33), breast (34), prostate gland (35), bladder (36, $37)$, endometrium $(10,38)$, uterine cervix $(38)$, and ovary $(12,13,39,40)$ and in hematopoietic malignancies (1), melanoma and non-melanoma skin cancers $(19,21,41)$, and neuroblastoma (16). The percentage of survivin-positive cases varies from $35 \%$ in gastric cancer (15) to $93 \%$ in primary and metastatic malignant melanoma (19), with expression in $51-86 \%$ of ovarian cancers $(12,13,40,42)$. Reported as a cytoplasmic stain (2, 14-16, 32, 43), survivin expression is seen by us and others $(11,32$, 39 , 44) predominantly in nuclei. Survivin is also assayed by RT-PCR, with $76 \%$ correlation between mRNA and nuclear survivin expression by IHC; results are $23 \%$ negative and $77 \%$ positive with both techniques (45).

Survivin expression may be a useful diagnostic, prognostic, and predictive marker in certain malignancies. The presence of serum anti-survivin antibodies in patients with lung and colorectal cancer may prove a novel diagnostic marker $(25,46)$. Survivin assay in urine may be easier and cheaper for diagnosis of urothelial carcinoma than cystoscopy (47).

Survivin may also prove to be a useful prognostic marker (2). Table 4 demonstrates the prognostic impact of survivin in neoplasms according to whether it is demonstrated by IHC in nuclei (IHCn), by IHC in cytoplasm (IHCc), by RT-PCR, by Western blot, or by RNase protection assay. In general, the presence of survivin indicates a carcinoma of unfavorable histology; advanced stage; decreased 5 -year, overall, and disease-free survival; and in- 


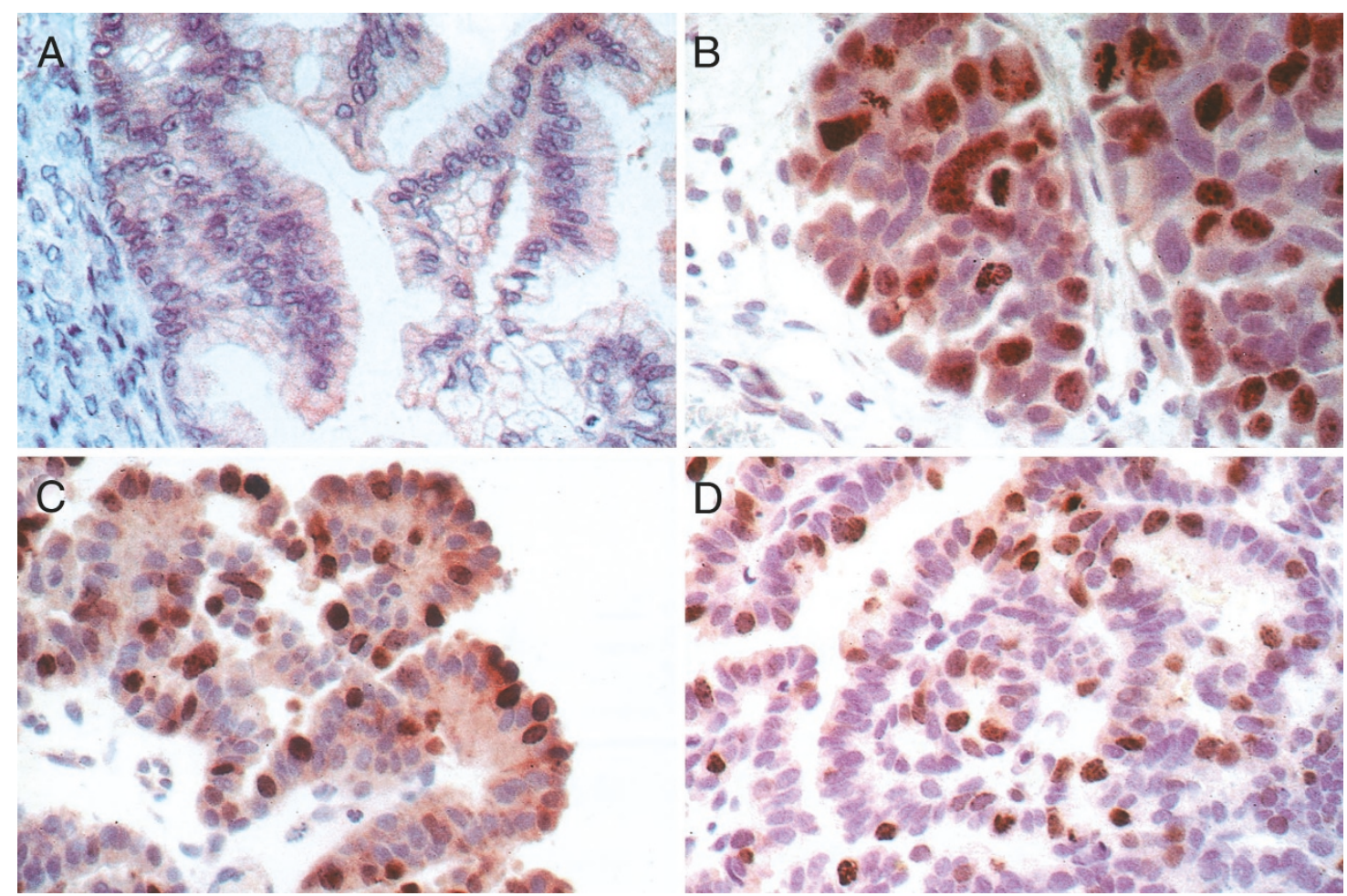

FIGURE 2. A, lack of nuclear survivin expression in an ovarian mucinous tumor. B-D, nuclear survivin expression in an ovarian poorly differentiated carcinoma and in two papillary serous carcinomas, respectively. Magnification, $400 \times$.

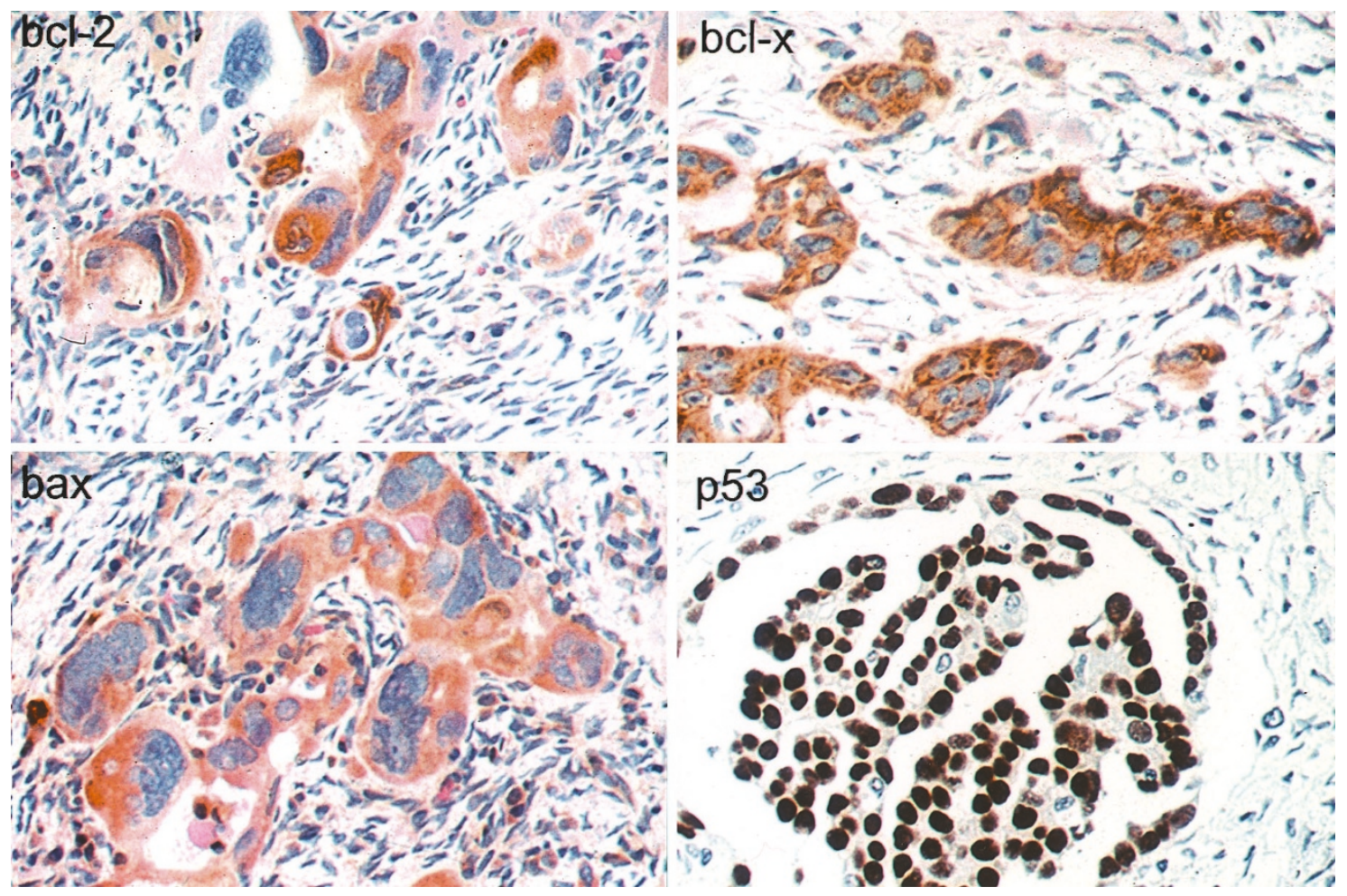

FIGURE 3. Serous carcinomas of the ovary with expression of cytoplasmic bcl-2, bax, and bcl-x and nuclear mutant p53. Magnification, 400×.

creased recurrence rate as compared with the case of carcinomas without survivin expression. This is most frequently seen with expression of survivin by IHCn, RT-PCR, Western blot, and/or RNase protec- tion assay. However, in some studies of neuroblastoma (16), laryngeal squamous cell (48), and colorectal carcinoma $(2,5,14,30)$, poor prognosis was demonstrated associated with IHCc. In prostate 
TABLE 2. Clinicopathologic Features in 49 Ovarian Carcinoma According to Survivin Expression

\begin{tabular}{|c|c|c|c|c|}
\hline & \multirow[b]{2}{*}{ Number Total } & \multicolumn{2}{|c|}{ Survivin } & \multirow[b]{2}{*}{$P$ Value } \\
\hline & & $\begin{array}{c}\text { Negative } \\
\text { (13) }\end{array}$ & $\begin{array}{c}\text { Positive } \\
\text { (36) }\end{array}$ & \\
\hline Median age (years) & $(49)$ & 57 & 63 & 0.0726 \\
\hline Range & & $29-76$ & $45-79$ & \\
\hline Histologic grade & (49) & & & 0.0014 \\
\hline 1 & $(7)$ & & $14 \%$ & \\
\hline 2 & (15) & & $87 \%$ & \\
\hline 3 & $(27)$ & & $81 \%$ & \\
\hline Histologic type & (49) & & & 0.0376 \\
\hline Endometrioid & $(2)$ & & $100 \%$ & \\
\hline Mucinous & $(5)$ & & $20 \%$ & \\
\hline Serous & (35) & & $80 \%$ & \\
\hline Poorly differentiated & $(7)$ & & $71 \%$ & \\
\hline Stage & $(46)$ & & & 0.3062 \\
\hline I & (3) & & $50 \%$ & \\
\hline II & $(2)$ & & $100 \%$ & \\
\hline III & (11) & & $64 \%$ & \\
\hline IV & $(30)$ & & $80 \%$ & \\
\hline bcl-2 expression & (49) & & & 0.8802 \\
\hline Negative & $(31)$ & & $74 \%$ & \\
\hline Positive & (18) & & $72 \%$ & \\
\hline bcl-x expression & (49) & & & 1.0000 \\
\hline Negative & (3) & & $67 \%$ & \\
\hline Positive & $(46)$ & & $74 \%$ & \\
\hline bax expression & (49) & & & \\
\hline Negative & (11) & & $91 \%$ & 0.2461 \\
\hline Positive & (38) & & $68 \%$ & \\
\hline p53 mutation & $(48)$ & & & 0.0414 \\
\hline Negative & (19) & & $58 \%$ & \\
\hline Positive & (29) & & $86 \%$ & \\
\hline
\end{tabular}

TABLE 3. Correlation of Survival with Expression of Survivin and Apoptotic Markers in 44 Ovarian Carcinoma Patients with Follow-Up

\begin{tabular}{|c|c|c|c|c|}
\hline \multirow{2}{*}{ Expression } & \multirow{2}{*}{ Number Total } & \multirow{2}{*}{ Number (\%) } & \multicolumn{2}{|c|}{$P$ Value Survival } \\
\hline & & & Overall & Disease-Free \\
\hline SURVIVIN & (44) & & 0.8139 & 0.7919 \\
\hline Negative & & $11(25 \%)$ & & \\
\hline Positive & & 33 (75\%) & & \\
\hline bcl-2 & (43) & & 0.2659 & 0.5131 \\
\hline Negative & & 27 (63\%) & & \\
\hline Positive & & 16 (37\%) & & \\
\hline bcl-x & (44) & & 0.1205 & 0.2111 \\
\hline Negative & & $3(7 \%)$ & & \\
\hline Positive & & $41(93 \%)$ & & \\
\hline bax & (44) & & 0.5818 & 0.8903 \\
\hline Negative & & $10(23 \%)$ & & \\
\hline Positive & & $34(77 \%)$ & & \\
\hline p53 & (44) & & 0.1998 & 0.1330 \\
\hline Negative & & 17 (39\%) & & \\
\hline Positive & & 27 (61\%) & & \\
\hline
\end{tabular}

cancer, neuroendocrine cells express survivin (35). Progression occurs in $63 \%$ of cancers with neuroendocrine differentiation, compared with $40 \%$ without. This suggests a trend to poorer prognosis of prostate cancers with neuroendocrine differentiation and survivin expression (35).

Overall survival in gastric cancer (32) and disease-free survival in urothelial bladder carcinoma (56) are improved in the presence of nuclear survivin expression (IHCn). In multivariate analysis, survivin was shown to be an independent favorable prognosticator in gastric cancer (32). Although not statistically significant, disease-free survival was 27.2 months in urothelial carcinomas with survivin expression, versus 9.9 months without survivin (56).

Pancreatic (57), gastric $(32,58)$, esophageal $(51)$, and urothelial (37) carcinomas show no association between survivin IHCc expression and patient survival. The gastric carcinomas were, in addition, studied with RT-PCR. The presence of cytoplasmic survivin (IHCc) in colorectal (14) and gastric (15) carcinoma was unrelated to histologic grade.

We show, in ovarian cancer, a $74 \%$ frequency of nuclear survivin expression that correlates with the $51-81 \%$ reported frequency by $\operatorname{IHCn}(12,13), 86 \%$ by RT-PCR (40), and $73 \%$ by IHCc (42). Although we noted no effect of survivin expression on overall or disease-free survival, there was a correlation between IHCn and poor prognostic markers (grade, histologic type, and p53 mutation). Yoshida et al. (39) show significantly shorter disease-free survival, and Takai et al. (12) show a significant association with proliferation, clinical stage, histologic grade, clinical outcome, and survival rate in ovarian cancers with nuclear survivin expression. IHCcexpressing ovarian cancers showed clinical resistance to taxol/platinum-based therapeutic regimes, with a lower clinical or pathological complete remission rate (42).

Other studies have related apoptotic markers to prognosis in ovarian carcinoma. Lohmann et al. (59), showed increased bcl-2 expression in patients with shortened overall and disease-free survival and showed increased bcl-x and bax expression with increased overall and disease-free survival, although results were not statistically significant. For patients whose carcinomas showed bcl-2-bax and bcl-2:bcl-x ratios of $<1$, there was a trend toward survival advantage. Mano et al. (60) showed significantly poorer survival in patients with Stage III-IV ovarian serous or endometrioid carcinomas expressing bcl-2. Initial response to chemotherapy was inversely related to bcl-2 expression, which was also an independent prognostic factor (60). In several other studies (61-64), bcl-2 expression was associated with favorable prognosis and low-grade carcinomas in ovarian cancer patients. Bax expression, particularly in bcl-2-negative cancers, correlated with a bad clinical outcome (63), or with improved prognosis, of independent prognostic significance (65). p53 mutation, on the other hand, appeared significantly more in high-grade cancers of advanced stage, with residual disease after surgery, and with decreased survival, being an independent prognostic indicator $(61,62,66)$. Munakata et al. (67) showed no relationship between bax expression and prognosis. Apoptotic index is shown to increase with grade, being low in tumors of low malignant potential and mucinous carcinomas (62, 


\begin{tabular}{|c|c|c|c|}
\hline Prognostic Parameter & Impact & Assay Method & Neoplasm/Carcinoma (References) \\
\hline \multirow[t]{4}{*}{ Unfavorable histology } & Aggressive disseminated disease & IHCc & Neuroblastoma (16) \\
\hline & & $\mathrm{IHCc}$ & Larynx squamous (48) \\
\hline & & IHCc/W blot & Skin, oral cavity Squamous (49) \\
\hline & & IHCn & Endometrial (10) \\
\hline \multirow[t]{3}{*}{ Advanced stage } & Significant association & RTPCR & Neuroblastoma (50) \\
\hline & & IHCc & Larynx Squamous (48) \\
\hline & & $\mathrm{IHCn}$ & Endometrial (10) \\
\hline 5-year survival rate & Decreased & IHCc & Colorectal $(2,5,14,30)$ \\
\hline \multirow[t]{6}{*}{ Overall survival } & Decreased & RTPCR & Lung non-small cell (29) \\
\hline & Decreased & RTPCR/IHCn & Esophageal $(33,51)$ \\
\hline & Decreased & W blot & Gliomas (52) \\
\hline & Decreased & RTPCR & Soft tissue sarcoma (53) \\
\hline & Decreased & $\mathrm{IHCn}$ & Larynx Squamous (48) \\
\hline & Decreased & $\mathrm{IHCn}$ & Endometrial (10) \\
\hline \multirow[t]{4}{*}{ Disease-free survival } & Decreased & $\mathrm{IHCc}$ & Urothelial (36) \\
\hline & Decreased & RTPCR & Hepatocellular (54) \\
\hline & Decreased & RTPCR/IHCn & Melanoma (45) \\
\hline & Decreased & IHCc & Larynx squamous (48) \\
\hline \multirow[t]{3}{*}{ Recurrence rate } & Increased & RNase PA & Neuroblastoma (55) \\
\hline & Increased & IHCc & Colorectal (30) \\
\hline & Increased & RTPCR & Hepatocellular (54) \\
\hline
\end{tabular}

IHCn: predominantly nuclear detection by immunohistochemistry.

IHCc: predominantly cytoplasmic detection by immunohistochemistry.

RTPCR: reverse transcriptase polymerase chain reaction.

W blot: Western blot.

RNase PA: RNase protection assay.

66). High apoptotic index has significantly correlated with high mitotic index, high-grade histology, and decreased overall survival (61), whereas an inverse relationship was noted between apoptotic index and bcl-2 expression.

bcl-2 is reported to be strongly expressed in surface epithelium of normal ovaries and in benign and borderline ovarian tumors, but weakly in carcinomas (69-71). bcl- $\mathrm{x}_{\mathrm{L}}$ and bax expression were higher in carcinoma than normal ovarian tissue (71). DNA demethylase (dMTase) is reported in almost $90 \%$ of ovarian carcinomas but only in $9 \%$ of non-cancerous ovaries (40). In dMTase-negative cancers $(40 \%)$ and benign ovary (91\%), survivin gene exon 1 was found to be methylated, compared with $79 \%$ unmethylated in dMTase-positive ovarian cancers (35). Exon 1 was methylated in $83 \%$ of survivin-negative cancers ( $86 \%$ were RT-PCR positive for survivin expression) (40). Thus, survivin gene exon 1 may be a target for demethylation by dMTase.

Inhibition of apoptosis is a common property of cancer cells, enabling them to increase their survival and facilitate their escape from immune surveillance and cytotoxic therapies. Survivin, as an inhibitor of apoptosis, appears to have a role in cancer progression or drug resistance $(5,42,72)$. Survivin has also been shown to be an inducible radioresistance factor in pancreatic cancer cells (67) and possibly also in nonsmall cell lung carcinoma (72).

Survivin phosphorylation on threonine $\left(\mathrm{Thr}^{34}\right)$ may be required to preserve cell viability at cell division. Manipulation of this pathway to regulate apoptosis may help in removal of cancer cells at mitosis (74). A phosphorylation-defective survivin mutant with alanine replacing threonine $\left(\mathrm{Thr}^{34} \rightarrow\right.$ Ala) triggered apoptosis in several melanoma cell lines and increased cell death induced by cisplatinum in vitro (20). In established melanomas in mice, this survivin mutant resulted in increased apoptosis, decreased proliferation, and inhibition of tumor growth by $60-70 \%$ (20). Thus, survivin may be a new target for antimelanoma therapeutic strategies. A survivin $\left(\mathrm{Thr}^{34} \rightarrow\right.$ Ala mutant adenovirus initiated the mitochondrial apoptotic pathway when used to infect cell lines of cervical, lung, colorectal, prostate, and breast carcinoma (22). It was as effective as taxol and more effective than adriamycin in inducing tumor cell apoptosis, and it increased taxol-induced cell death (22). In SCID mice injected with MCF-7 breast carcinoma cell lines infected with this mutant adenovirus, de novo tumor formation was suppressed, tumor growth was inhibited by $40 \%$, and intraperitoneal spread decreased, with an associated increased apoptosis and decreased proliferation (22). Thus, adenoviral targeting of the survivin pathway may prove to be a novel cancer gene therapy for certain tumors (22). Inhibitors of cyclin-dependent kinases such as Flavopiridol also prevent $\mathrm{Thr}^{34}$ phosphorylation and have antitumor effect in renal, prostate, and colon cancer and in non-Hodgkins lymphoma (75).

Blockage of survivin expression may also be used therapeutically in cancers. Intratumoral injection of plasmids encoding antisense survivin blocks survivin expression, stimulates generation of tumorspecific cytotoxic $\mathrm{T}$ lymphocytes, decreases tumor 
growth, and may be a beneficial treatment for large cell lymphomas (18). Antisense oligonucleotides that reduce survivin expression in tumor cells induce apoptosis, decrease colony formation in soft agar, and sensitize tumor cells to chemotherapy $(18,19,21,76)$. Survivin antisense or survivin dominant negative mutant (Cystein $84 \rightarrow$ Ala) transfection of model keratinocyte and malignant melanoma cell lines resulted in decreased endogenous survivin, increased apoptotic cells, and decreased proliferation $(19,21)$. This therapeutic targeting of survivin may be useful in management of recurrent or advanced basal and squamous cell carcinoma, and melanoma, the majority of which $(81 \%, 92 \%$, and $93 \%$, respectively) express survivin $(19,21)$. In a lung adenocarcinoma cell line, antisense oligonucleotides targeting different regions of survivin mRNA downregulated survivin mRNA by $70 \%$, induced apoptosis (increasing caspase-3 activity, nuclear condensation and fragmentation, and trypan blue uptake), and sensitized tumor cells to the chemotherapeutic agent etoposide (76). Normal blood leukocytes, with minimal survivin mRNA, were unaffected. The molecular relationship between effector cell protease receptor-1 (EPR-1) and survivin, whereby $\mathrm{ZnSO}_{4}$ induction of an EPR-1 mRNA suppresses endogenous survivin expression, suggests a potential treatment of cancer with EPR-1 (77). Apoptosis is increased and cell proliferation inhibited.

Survivin may be required for tumor angiogenesis because it is highly expressed in newly formed blood vessels in response to vascular endothelial growth factor (VEGF) and basic fibroblast growth factor and mediates angiopoietin inhibition of endothelial cell apoptosis (78-81). Hence, therapies inhibiting survivin expression or function may prevent tumors from acquiring an adequate blood supply (18). Antisense oligonucleotide to survivin is shown to suppress de novo expression of survivin in endothelial cells by VEGF (23).

Cytotoxic T lymphocyte responses against two survivin-deduced peptide epitopes are described in peripheral blood from chronic lymphatic leukemia patients and in lymph nodes with metastatic melanoma (24). Circulating antibodies to survivin are detected in serum of patients with colonic and lung cancer $(25,46)$. In vitro, survivin induced specific CD8+ effector T cells (82). Thus, survivin may be a target for anticancer immunotherapeutic strategies (24).

We show a significant correlation between survivin expression (IHCn) and p53 mutation (both with anti-apoptotic functions) in ovarian cancers. This relationship is explained by the recent demonstration of wild-type p53 repressing survivin expression at both mRNA and protein levels, binding the survivin promoter $(83,84)$. This association, however, is not always the case in ovarian cancer with cytoplasmic survivin expression (42). In colorectal carcinoma, p53 abnormalities were not shown to correlate with IHCc survivin expression (14), although the latter was strongly associated with bcl-2 expression and reduced apoptotic index (14). Survivin expression (IHCc), even in bcl-2-negative colorectal cancers, also resulted in reduced apoptotic index (14). Similarly, in gastric (15) and breast carcinoma (34), cytoplasmic survivin was significantly associated with low apoptotic index, which, in breast carcinoma (34), was an independent prognostic factor associated with poor survival. In ovarian cancers, we fail to show a correlation between nuclear survivin expression and bcl-2 or bcl-x, all apoptotic inhibitors. On the other hand, Lu et al. (15) showed that cytoplasmic survivin expression significantly segregated gastric cancers with p53 and bcl-2 positivity. Apoptotic index was significantly decreased compared with that in survivinnegative tumors (15). Thus, correlation between different apoptotic markers varies from negative (bcl-2, p53, and apoptotic index [30, 57, 62]; survivin and p53 [14, 30]; survivin and bcl-2, bcl-x, bax, this study; survivin mRNA and apoptotic index [58]) to inverse (bcl-2 and p53 [64, 66]; survivin and apoptotic index $[14,31]$ ) to positive (survivin and bcl-2 [14, 15]; survivin and apoptotic index [57]; survivin and mutant p53, Lu et al. [15], Sarela et al. [57], and this study).

Grabowski et al. (51) report the translocation of survivin during carcinogenesis, with cytoplasmic localization in basal layers of the normal esophageal squamous mucosa, in high-grade dysplasia and in carcinoma, with, in addition, nuclear localization in high-grade dysplasia and the associated carcinomas. In hepatocellular carcinoma, the predominant function of survivin is shown to be its cell cycle nuclear distribution, not the cytoplasmic caspase-3-dependent antiapoptotic effect (11). The differences of the amino-acid sequence of the carboxy-terminal domain of survivin are shown to be responsible for its cytoplasmic localization and the nuclear localization of its splicing variant, survivin $\Delta$ Ex 3 (51). Thus, several reports (Table 4) show nuclear survivin immunostain to have prognostic significance, possibly related to its cell cycle effect, whereas cytoplasmic survivin, with its antiapoptotic effect, has no prognostic significance (32, $37,51,57,58)$. Nuclear survivin expression has not been shown by us to be an independent prognostic or predictive factor to identify ovarian cancer patients at increased risk of recurrence or of poor overall and/or disease-free survival. Nevertheless, nuclear survivin expression, present in the majority of the ovarian carcinomas we studied, did correlate with poor prognostic factors (high histologic grade, mutant p53, poor histologic type) and may predict response to antisurvivin therapies that induce apo- 
ptosis reduction as a result of survivin expression (14).

\section{Acknowledgment: We thank Judy Dunbar for secre- tarial support.}

\section{REFERENCES}

1. Ambrosini G, Adida C, Altieri DC. A novel anti-apoptosis gene, survivin, expressed in cancer and lymphoma. Nat Med 1997;3:917-21.

2. Altieri DC, Marchisio C. Survivin apoptosis: an interloper between cell death and cell proliferation in cancer. Lab Invest 1999;79:1327-33.

3. Altieri DC. The molecular basis and potential role of survivin in cancer diagnosis and therapy. Trends Mol Med 2001;7: 542-7.

4. Deveraux QL, Reed JC. IAP family proteins-suppressors of apoptosis. Genes Dev 1999;13:239-52.

5. LaCasse EC, Baird S, Korneluk RG, MacKenzie AE. The inhibitors of apoptosis (IAPs) and their emerging role in cancer. Oncogene 1998;17:3247-59.

6. Reed JC. The survivin saga goes in vivo. J Clin Invest 2001; 108:965-9.

7. Geske FJ, Gerschenson LE. The biology of apoptosis. Hum Pathol 2001;32:1029-38.

8. Saikumar P, Dong Z, Mikhailov V, Denton M, Weinberg JM, Venkatachalam MA. Apoptosis: definition, mechanisms, and relevance to disease. Am J Med 1999;107:489-506.

9. Tamm I, Wang Y, Sausville E, Scudiero DA, Vigna W, Oltersdorf $\mathrm{T}$, et al. IAP-family protein survivin inhibits caspase activity and apoptosis induced by Fas (CD95), bax, caspases, and anticancer drugs. Cancer Res 1998;58:5315-20.

10. Takai N, Miyazaki T, Nishida M, Nasu K, Miyakawa I. Survivin expression correlates with clinical stage, histological grade, invasive behavior and survival rate in endometrial carcinoma. Cancer Lett 2002;184:105-16.

11. Ito T, Shiraki K, Sugimoto K, Yamanaka T, Fujikawa K, Ito M, et al. Survivin promotes cell proliferation in human hepatocellular carcinoma. Hepatology 2000;31:1080-5.

12. Takai N, Miyazaki T, Nishida M, Nasu K, Miyakawa I. Expression of survivin is associated with malignant potential in epithelial ovarian carcinoma. Int J Mol Med 2002;10:211-6.

13. Sui L, Dong Y, Ohno M, Watanabe Y, Sugimoto K, Tokuda M. Survivin expression and its correlation with cell proliferation and prognosis in epithelial ovarian tumors. Int J Oncol 2002; 21:315-20.

14. Kawasaki H, Altieri DC, Lu CD, Toyoda M, Tenjo T, Tanigawa $\mathrm{N}$. Inhibition of apoptosis by survivin predicts shorter survival rates in colorectal cancer. Cancer Res 1998;58:5071-4.

15. Lu CD, Altieri DC, Tanigawa N. Expression of a novel antiapoptosis gene, survivin, correlated with tumor cell apoptosis and p53 accumulation in gastric carcinomas. Cancer Res 1998;58:1808-12.

16. Adida C, Berrebi D, Peuchmaur M, Reyes-Mugica M, Altieri DC. Anti-apoptosis gene, survivin, and prognosis of neuroblastoma [letter]. Lancet 1998;351:882-3.

17. Survivin apoptosis [editorial]. Lab Invest 1999;79:1325.

18. Kanwar JR, Shen W-P, Kanwar RK, Berg RW, Krissansen GW. Effects of survivin antagonists on growth of established tumors and B7-1 immunogene therapy. J Natl Cancer Inst 2001;93:1541-52.

19. Grossman D, McNiff JM, Li F, Altieri DC. Expression and targeting of the apoptosis inhibitor, survivin, in human melanoma. J Invest Dermatol 1999;113:1076-81.

20. Grossman D, Kim PJ, Schechner JS, Altieri DC. Inhibition of melanoma tumor growth in vivo by survivin targeting. Proc Natl Acad Sci U S A 2001;98:635-40.
21. Grossman D, McNiff JM, Li F, Altieri DC. Expression of the apoptosis inhibitor, survivin, in nonmelanoma skin cancer and gene targeting in a keratinocyte cell line. Lab Invest 1999;79:1121-6.

22. Mesri M, Wall NR, Li J, Kim RW, Altieri DC. Cancer gene therapy using a survivin mutant adenovirus. J Clin Invest 2001;108:981-90.

23. Mesri M, Morales-Ruiz M, Ackermann EJ, Bennett CF, Pober JS, Sessa WC, et al. Suppression of vascular endothelial growth factor-mediated endothelial cell protection by survivin targeting. Am J Pathol 2001;158:1757-65.

24. Anderson MH, Pederson LO, Becker JC, Straten PT. Identification of a cytotoxic T lymphocyte response to the apoptosis inhibitor protein survivin in cancer patients. Cancer Res 2001;61:869-72.

25. Rohayem J, Diestelkoetter P, Weigle B, Oehmichen A, Schmitz M, Mehlhorn J, et al. Antibody response to the tumor-associated inhibitor of apoptosis protein survivin in cancer patients. Cancer Res 2000;60:1815-7.

26. Buolamwini JK. Novel anticancer drug discovery. Curr Opin Chem Biol 1999;3:500-9.

27. Rosai J, editor. Ackerman's surgical pathology. Vol. 2. 8th ed. St. Louis: Mosby; 1996. p. 1461-539.

28. Goel A, Abou-Ellela A, DeRose PB, Cohen C. The prognostic significance of proliferation in prostate cancer: an image cytometric quantitation of MIB-1. J Urol Pathol 1996;4:21325.

29. Monzo M, Rosell R, Felip E, Astudillo J, Sanchez JJ, Maestre $\mathrm{J}$, et al. A novel anti-apoptosis gene: re-expression of survivin messenger RNA as a prognosis marker in non-small-cell lung cancers. J Clin Oncol 1999;17:2100-4.

30. Sarela AI, Scott N, Ramsdale J, Markham AF, Guillou PJ. Immunohistochemical detection of the anti-apoptosis protein, survivin, predicts survival after curative resection of stage II colorectal carcinomas. Ann Surg Oncol 2001;8:305-10.

31. Satoh K, Kaneko K, Hirota M, Masamune A, Satoh A, Shimosegawa T. Expression of survivin is correlated with cancer cell apoptosis and is involved in the development of human pancreatic duct cell tumors. Cancer 2001;92:271-8.

32. Okada E, Murai Y, Matsui K, Isizawa S, Cheng C, Masuda M, et al. Survivin expression in tumor cell nuclei is predictive of a favorable prognosis in gastric cancer patients. Cancer Lett 2001;163:109-16.

33. Kato J, Kuwabara Y, Mitani M, Shinoda N, Sato A, Toyama T, et al. Expression of survivin in esophageal cancer: correlation with the prognosis and response to chemotherapy. Int J Cancer 2001;95:92-5.

34. Tanaka K, Iwamoto S, Gon G, Nohara T, Iwamoto M, Tanigawa N. Expression of survivin and its relationship to loss of apoptosis in breast carcinomas. Clin Cancer Res 2000;6:12734.

35. Xing N, Qian J, Bostwick D, Bergstralh E, Young CY. Neuroendocrine cells in human prostate over-express the antiapoptosis protein survivin. Prostate 2001;48:7-15.

36. Swana HS, Grossman D, Anthony JN, Weiss RM, Altieri DC. Tumor content of the antiapoptosis molecule survivin and recurrence of bladder cancer. N Engl J Med 1999;341:452-3.

37. Nakanishi K, Tominaga S, Hiroi S, Kawai T, Aida S, Kasamatsu $\mathrm{H}$, et al. Expression of survivin does not predict survival in patients with transitional cell carcinoma of the upper urinary tract. Virchows Arch 2002;441:559-63.

38. Saitoh Y, Yaginuma Y, Ishikawa M. Analysis of bcl-2, bax and survivin genes in uterine cancer. Int J Oncol 1999;15:137-41.

39. Yoshida H, Ishiko O, Sumi T, Matsumoto Y, Ogita S. Survivin, bcl-2 and matrix metalloproteinase-2 enhance progression of clear cell- and serous-type ovarian carcinomas. Int J Oncol 2001;19:537-42.

40. Hattori M, Sakamoto H, Satoh K, Yamamoto T. DNA demethylase is expressed in ovarian cancers and the expres- 
sion correlates with demethylation of $\mathrm{CpG}$ sites in the promoter region of c-erbB-2 and survivin genes. Cancer Lett 2001;169:155-64.

41. Chiodino C, Cesinaro AM, Ottani D, Fantini F, Giannetti A, Trentini GP, et al. Expression of the novel inhibitor of apoptosis survivin in normal and neoplastic skin. J Invest Dermatol 1999;113:415-8.

42. Zaffaroni N, Pennati M, Colella G, Perego P, Supino R, Gatti L, et al. Expression of the anti-apoptotic gene survivin correlates with taxol resistance in human ovarian cancer. Cell Mol Life Sci 2002;59:1406-12.

43. Gianani R, Jarboe E, Orlicky D, Frost M, Bobak J, Lehner R, Shroyer KR. Expression of survivin in normal, hyperplastic, and neoplastic colonic mucosa. Hum Pathol 2001;32:119-25.

44. Konno R, Yamakawa H, Utsunomiya H, Ito K, Sato S, Yajima A. Expression of survivin and bcl-2 in the normal human endometrium. Mol Hum Reprod 2000;6:529-34.

45. Gradilone A, Gazzaniga P, Ribuffo D, Scarpa S, Cigna E, Vasaturo F, et al. Survivin, bcl-2, bax, and bcl-x gene expression in sentinel lymph nodes from melanoma patients. J Clin Oncol 2003;21:306-12.

46. Yagihashi A, Asanuma K, Nakamura M, Araya J, Mano Y, Torigoe $\mathrm{T}$, et al. Detection of anti-survivin antibody in gastrointestinal cancer patients. Clin Chem 2001;47:1729-31.

47. Sharp JD, Hausladen DA, Maher MG, Wheeler MA, Altieri DC, Weiss RM. Bladder cancer detection with urinary survivin, an inhibitor of apoptosis. Front Biosci 2002;7:e36-41.

48. Dong Y, Sui L, Watanabe Y, Sugimoto K, Tokuda M. Survivin expression in laryngeal squamous cell carcinomas and prognostic implications. Anticancer Res 2002;22:2377-84.

49. Lo Muzio L, Staibano S, Pannone G, Mignogna MD, Mariggio A, Salvatore G, et al. Expression of the apoptosis inhibitor survivin in aggressive squamous cell carcinoma. Exp Mol Pathol 2001;70:249-54.

50. Islam A, Kageyama H, Takada N, Kawamoto T, Takayasu H, Isogai E, et al. High expression of survivin, mapped to 17q25, is significantly associated with poor prognostic factors and promotes cell survival in human neuroblastoma. Oncogene 2000;19:617-23.

51. Grabowski P, Kuhnel T, Muhr-Wilkenshoff F, Heine B, Stein $\mathrm{H}$, Hopfner $\mathrm{M}$, et al. Prognostic value of nuclear survivin expression in esophageal squamous cell carcinoma. Cancer Res 2003;88:115-9.

52. Chakravarti A, Noll E, Black PM, Finkelstein DF, Finkelstein DM, Dyson NJ, et al. Quantitatively determined survivin expression levels are of prognostic value in human gliomas. J Clin Oncol 2002;20:1063-8.

53. Kappler M, Kohler T, Kampf C, Diestelkotter P, Wurl P, Schmitz M, et al. Increased survivin transcript levels: an independent negative predictor of survival in soft tissue sarcoma patients. Int J Cancer 2001;95:360-3.

54. Ikeguchi M, Ueda T, Sakatani T, Hirooka Y, Kaibara N. Expression of survivin messenger RNA correlates with poor prognosis in patients with hepatocellular carcinoma. Diagn Mol Pathol 2002;11:33-40.

55. Azuhata T, Scott D, Takamizawa S, Wen J, Davidoff A, Fukuzawa $\mathrm{M}$, et al. The inhibitor of apoptosis protein survivin is associated with high-risk behavior of neuroblastoma. J Pediatr Surg 2001;36:1785-91.

56. Lehner R, Lucia MS, Jarboe EA, Orlicky D, Shroyer AL, McGregor JA, et al. Immunohistochemical localization of the IAP protein survivin in bladder mucosa and transitional cell carcinoma. Appl Immunohistochem 2002;10:134-8.

57. Sarela AI, Verbeke CS, Ramsdale J, Davies CL, Markham AF, Guillou PJ. Expression of survivin, a novel inhibitor of apoptosis and cell cycle regulatory protein, in pancreatic adenocarcinoma. Br J Cancer 2002;86:886-92.
58. Ikeguchi M, Kaibara N. Changes in survivin messenger RNA level during cisplatin treatment in gastric cancer. Int J Mol Med 2001;8:661-6.

59. Lohmann CM, League AA, Clark WS, Lawson D, DeRose PB, Cohen C. Bcl-2:bax and bcl-2:bcl-x ratios by image cytometric quantitation of immunohistochemical expression in ovarian carcinoma: correlation with prognosis. Cytometry 2000;42:61-6.

60. Mano Y, Kikuchi Y, Yamamoto K, Kita T, Hirata J, Tode T, et al. Bcl-2 as a predictor of chemosensitivity and prognosis in primary epithelial ovarian cancer. Eur J Cancer 1999;35: 1214-9.

61. Herod JJ, Eliopoulos AG, Warwick J, Niedobitek G, Young LS, Kerr DJ. The prognostic significance of bcl-2 and p53 expression in ovarian carcinoma. Cancer Res 1996;56:2178-84.

62. Diebold J, Baretton G, Felchner M, Meier W, Dopfer K, Schmidt M, et al. Bcl-2 expression, p53 accumulation, and apoptosis in ovarian carcinomas. Am J Clin Pathol 1996;105: 341-9.

63. Marx D, Binder C, Meden H, Lenthe T, Ziemek T, Hiddemann T, et al. Differential expression of apoptosis associated genes bax and bcl-2 in ovarian cancer. Anticancer Res 1997; 17:2233-40.

64. Henricksen R, Wilander E, Oberg K. Expression and prognostic significance of bcl-2 in ovarian tumours. Br J Cancer 1995;72:1324-9.

65. Baekelandt M, Holm R, Nesland JM, Trope CG, Kristensen GB. Expression of apoptosis-related proteins is an independent determinant of patient prognosis in advanced ovarian cancer. J Clin Oncol 2000;18:3775-81.

66. Ben-Hur H, Gurevich P, Huszar M, Ben-Arie A, Berman V, Tendler Y, et al. Apoptosis and apoptosis-related proteins in the epithelium of human ovarian tumors: immunohistochemical and morphometric studies. Eur J Gynecol Oncol 1999;20:249-53.

67. Munakata S, Enomoto T, Tsujimoto M, Otsuki Y, Miwa H, Kanno $\mathrm{H}$, et al. Expressions of Fas ligand and other apoptosis-related genes and their prognostic significance in epithelial ovarian neoplasms. Br J Cancer 2002;82:1446-52.

68. Yamasaki F, Tokunaga O, Sugimori H. Apoptotic index in ovarian carcinoma: correlation with clinicopathologic factors and prognosis. Gynecol Oncol 1997;66:439-48.

69. Chan WY, Cheung KK, Schorge JO, Huang LW, Welch WR, Bell DA, et al. Bcl-2 and p53 protein expression, apoptosis, and p53 mutation in human epithelial ovarian cancers. Am J Pathol 2000;156:409-17.

70. Wehrli BM, Krajewski S, Gascoyne RD, Reed JC, Gilks CB. Immunohistochemical analysis of bcl-2, bax, mcl-1, and bcl-x expression in ovarian surface epithelial tumors. Int J Gynecol Pathol 1998;17:255-60.

71. Marone M, Scambia G, Mozzetti S, Ferrandina G, Iacovella S, De Pasqua A, et al. Bcl-2, bax, bcl- $\mathrm{X}_{\mathrm{L}}$, and bcl- $\mathrm{X}_{\mathrm{S}}$ expression in normal and neoplastic ovarian tissues. Clin Cancer Res 1998;4:517-24.

72. Joseph B, Lewensohn R, Zhivotovsky B. Role of apoptosis in the response of lung carcinomas to anti-cancer treatment. Ann N Y Acad Sci 2000;926:204-16.

73. Asanuma K, Moriai R, Yajima T, Yagihashi A, Yamada M, Kobayashi D, et al. Survivin as a radioresistance factor in pancreatic cancer. Jpn J Cancer Res 2000;91:1204-9.

74. O'Conner DS, Grossman D, Plescia J, Li F, Zhang H, Villa A, et al. Regulation of apoptosis at cell division by $\mathrm{p} 34^{\mathrm{cdc} 2}$ phosphorylation of survivin. Proc Natl Acad Sci U S A 2000; 97:13103-7.

75. Senderowicz AM, Headlee D, Stinson SF, Lush RM, Kalil N, Villalba L, et al. Phase I trial of continuous infusion flavopiridol, a novel cyclin-dependent kinase inhibitor, in patients with refractory neoplasms. J Clin Oncol 1998;16:2986-99. 
76. Olie RA, Simoes-Wust AP, Baumann B, Leech SH, Fabbro D, Stahel RA, et al. A novel antisense oligonucleotide targeting survivin expression induces apoptosis and sensitizes lung cancer cells to chemotherapy. Cancer Res 2000;60:2805-9.

77. Ambrosini G, Adida C, Sirugo G, Altieri DC. Induction of apoptosis and inhibition of cell proliferation by survivin gene targeting. J Biol Chem 1998;273:11177-82.

78. Kawasaki H, Toyoda M, Shinohara H, Okuda J, Watanabe I, Yamamoto T, et al. Expression of survivin correlates with apoptosis, proliferation, and angiogenesis during human colorectal tumorigenesis. Cancer 2001;91:2026-32.

79. O'Connor DS, Schechner JS, Adida C, Mesri M, Rothermel $\mathrm{AL}, \mathrm{Li} \mathrm{F}$, et al. Control of apoptosis during angiogenesis by survivin expression in endothelial cells. Am J Pathol 2000; 156:393-8.

80. Tran J, Rak J, Sheehan C, Saibil SD, LaCasse E, Korneluk RG, et al. Marked induction of the IAP family antiapoptotic pro- teins survivin and XIAP by VEGF in vascular endothelial cells. Biochem Biophys Res Commun 1999;264:781-8.

81. Papapetropoulos A, Fulton D, Mahboubi K, Kalb RG, O'Connor DS, Li F, et al. Angiopoietin-1 inhibits endothelial cell apoptosis via the Akt/survivin pathway. J Biol Chem 2000;275:9102-5.

82. Schmitz M, Diestelkoetter P, Weigle B, Schmachtenberg F, Stevanovic S, Ockert D, et al. Generation of survivin-specific CD8 $+\mathrm{T}$ effector cells by dendritic cells pulsed with protein or selected peptides. Cancer Res 2000;60:4845-9.

83. Mirza A, McGuirk M, Hockenberry TN, Wu Q, Ashar H, Black $\mathrm{S}$, et al. Human survivin is negatively regulated by wild-type p53 and participates in p53-dependent apoptotic pathway. Oncogene 2002;21:2613-22.

84. Hoffman WH, Biade S, Zilfou JT, Chen J, Murphy M. Transcriptional repression of the anti-apoptotic survivin gene by wild type p53. J Biol Chem 2002;277:3247-57. 